\title{
Criteria for Selecting Optimal Nitrogen Fertilizer Rates for Precision Agriculture
}

\author{
Bruno Basso $^{* 1,2,3}$, Davide Cammarano ${ }^{1}$, Peter R. Grace ${ }^{2,3}$, Giovanni Cafiero ${ }^{1}$, \\ Luigi Sartori ${ }^{4}$, Michele Pisante ${ }^{5}$, Giuseppe Landi ${ }^{1}$, Sergio De Franchi ${ }^{1}$, Francesco Basso ${ }^{1}$ \\ ${ }^{1}$ Dipartimento di Scienze dei Sistemi Colturali Forestali e dell'Ambiente, \\ Università della Basilicata, completare l'indirizzo Potenza, Italy \\ ${ }^{2}$ Kellogg Biological Station, Michigan State University, Hickory Corner, \\ completare l'indirizzo Michigan, USA \\ ${ }^{3}$ Institute for Renewable Resources, Queensland University of Technology, \\ completare l'indirizzo Brisbane, Australia \\ ${ }^{4}$ Dipartimento dei Sistemi Agroforestali e del Territorio, Univeristà di Padova, \\ completare l'indirizzo Legnaro, Padova, Italy \\ ${ }^{5}$ Dipartimento di Scienze degli Alimenti, Università di Teramo, \\ completare l'indirizzo Mosciano S.Angelo, Teramo, Italy
}

Received: 1 September 2009. Accepted: 28 October 2009.

\begin{abstract}
Yield rates vary spatially and maps produced by the yield monitor systems are evidence of the degree of withinfield variability. The magnitude of this variability is a good indication of the suitability of implementing a spatially variable management plan. Crop simulation models have the potential to integrate the effects of temporal and multiple stress interaction on crop growth under different environmental and management conditions. The strength of these models is their ability to account for stress by simulating the temporal interaction of stress on plant growth each day during the season.

The objective of paper is to present a procedure that allows for the selection of optimal nitrogen fertilizer rates to be applied spatially on previously identified management zones through crop simulation modelling. The integration of yield maps, remote sensing imagery, ground truth measurements, electrical resistivity imaging allowed for the identifications of three distinct management zones based on their ability to produce yield and their stability over time (Basso et al., 2009). After validating the model, we simulated $7 \mathrm{~N}$ rates from 0 to $180 \mathrm{~kg} \mathrm{~N} / \mathrm{ha}$ with a $30 \mathrm{~kg}$ $\mathrm{N} /$ ha increment. The model results illustrate the different $\mathrm{N}$ responses for each of the zone. The analysis allowed us to identify the optimal $\mathrm{N}$ rate for each of the zone based on agronomic, economic and environmental sustainability of $\mathrm{N}$ management.
\end{abstract}

Key-words: simulation models, wheat, variable rate nitrogen, management zones, precision agriculture.

\section{Introduction}

Appropriate nitrogen management is one of the main challenges of agriculture production and for the environment. Raun and Johnson (1999) stated that Nitrogen Use Efficiency (NUE) defined as the amount of $\mathrm{N}$ used for producing grains, might be as low as $33 \%$ for cereals and that an increase of $1 \%$ in NUE would lead to a global savings of $\$ 234$ million US dollars. Under field conditions $\mathrm{N}$ losses are mainly due to volatilization of $\mathrm{NH}_{3}$ from leaves of $\mathrm{N}$-rich plants, soil denitrification and nitrates leaching (Raun and Johnson, 1999). Therefore to reduce such losses a better and more efficient way of applying $\mathrm{N}$ is necessary.

From an economic point of view the optimal Nitrogen $(\mathrm{N})$ fertilizer amount should be the rate at which the farmer's financial return is maximized and it known as Economic Optimum Rate (EOR). The optimal $\mathrm{N}$ amount $\left(\mathrm{N}_{\mathrm{opt}}\right)$ varies between cultivar, site location and be- 
tween years (Samborski et al., 2009), for the same field cropped with the same cultivar the $\mathrm{N}_{\text {opt }}$ is not constant across the field because of the spatial variability of crop growing conditions and soil properties (Pierce and Novak, 1999).

The determination of the $\mathrm{N}_{\text {opt }}$ is made by subtracting the crop $\mathrm{N}$ uptake from the soil $\mathrm{N}$ supply and $\mathrm{N}$ inputs. One way to quantify $\mathrm{N}_{\mathrm{opt}}$ is to base the estimation of final yield upon the "expected yield", which is function of known crop average yield and its $\mathrm{N}$ content (Meisinger, 1984). However, long-term experiments have showed that yield might be difficult to predict because the yield potential can vary substantially between years (Scharf et al., 2006) and the $\mathrm{N}$ content will vary as function of cultivar, and $\mathrm{N}$ supply. This is because of the unpredictability of weather conditions, in fact a year with lower rainfall causes a reduction of biomass yield and low crop $\mathrm{N}$ uptake (Ritchie and Basso 2008). Moreover, the spatial distribution of soil properties interacts with weather conditions, determining a within-field spatial variability of crop growth even for the same growing season. For example, the different distribution of clay and sand content and their interaction with the growing season rainfall can affect the soil water holding capacity, which will affect crop growth in the field and its $\mathrm{N}$ uptake (Lory and Scharf, 2003; Kyveryga et al., 2009).

Another method used to estimate $\mathrm{N}$ fertilizer requirements is analyses of soil samples. This method takes into account the soil $\mathrm{N}$ supply, which influence crop $\mathrm{N}$ uptake throughout the growing season. Soil $\mathrm{N}$ can be divided into two components, the soil mineral $\mathrm{N}$ (SMN), which is the $\mathrm{N}$ immediately available to crops; and the organic $\mathrm{N}(\mathrm{ON})$, that will be mineralized and be available to crops through the growing season. The test for SMN is made before planting, and it is known as the pre-plant Nitrate test (PPNT) and/or during the vegetation period (pre-sidedress Nitrate test; PSNT) (Schmidt et al., 2009; Bundy and Andraski, 2004). However, Everett and Pierce (1996) suggested that the fertilization based on PPNT or PSNT is viable compared to a fixed $\mathrm{N}$ rate only if a significant SMN variation is found between fields or between years.

Along with soil $\mathrm{N}$, the assessment includes the estimation of soil $\mathrm{N}$ mineralization rates. $\mathrm{N}$ mineralization rates can be estimated under field conditions by using a reference plot with no $\mathrm{N}$ applications. But several studies found that the net $\mathrm{N}$ mineralization is site-specific and affected by weather conditions and amount of $\mathrm{N}$ applied in the fertilized plots (Blankenau et al., 2000). Laboratory experiments such as incubation procedures, assessment of microbial biomass activity, and chemical soil extractions might estimate a potential $N$ available to crops but under field conditions such potential may vary considerably and that is why those tests are used only in research studies rather than for practical agronomic decisions (Rice et al., 1995; Kitchen and Goulding, 2001).

The estimation of crop $\mathrm{N}$ content is an alternative method to estimate the $\mathrm{N}$ fertilization rates, because the crop is also a good indicator of the soil $\mathrm{N}$ at certain point during the growing season. In fact, the crop $\mathrm{N}$ content is function of soil $\mathrm{N}$ content, $\mathrm{N}$ mineralization rates, crop residues, soil water content, root growth, and $\mathrm{N}$ uptake efficiency (Rice et al., 1995).

There are several methods for assessing crop $\mathrm{N}$ status such as the total crop $\mathrm{N}$ concentration, and the plant petiole nitrate recommendation. The former, is done in the laboratory but for field application is time-consuming and few plant samplings might be not representative of the spatial variation of crop N. The latter, has been developed to make decision on the time and the rate of $\mathrm{N}$ fertilization directly into the field. For example, on potato crop the petiole test has been widely used for a quick assessment of crop N status (Zhang et al., 1996; Phillips et al., 2004). However, the nitrate concentration in the petiole varies according the sampling dates, position of the petiole on the plant, plant age, cultivar, time of the day when samples are collect, and weather condition prior to the test such as drought or rainfall (Vitosh and Silva, 1996).

Another non-destructive method to determine crop $\mathrm{N}$ status is the use of the optical transmission measurements with a hand-held chlorophyll meter such as Minolta SPAD-502 (Minolta, Japan). The instrument measures the leaf red transmittance at $690 \mathrm{~nm}$ and the near infrared transmittance at $940 \mathrm{~nm}$, which are found to be a measure of chlorophyll level in crops. The use of the hand-held chlorophyll meter is time consuming, and its values are affected by the leaf water status, and the specific leaf weight (Schlemmer et al., 2005). Moreover, the instrument measures only one point of the last fully developed leaf, but the nitrogen distribu- 
tion is not uniform within the leaf (Lemaire and Gastal, 1997). At canopy level, the chlorophyll meter does not give accurate values of nitrogen content because the canopy nitrogen distribution follows a vertical gradient distribution within the canopy. The nitrogen content decreases in the lower leaf layers, and the decrease is linearly related with decreasing in light intensity (Grindlay, 1997); moreover, it is also limited to point measurements and cannot practically be deployed spatially across a large field.

Remotely sensed vegetation indices can be used for the estimation of crop N, and indices such as the Normalized Difference Vegetation Indices (NDVI; Rouse et al., 1973) has been extensively used in commercial sensors, such as the Yara N-Sensor/FieldScan (Yara International, ASA, Oslo, Norway), GreenSeeker (N Tech Industries, Inc., Ukiah, CA) and the Crop Circle (Holland Scientific, Lincoln, NE). NDVI is affected by the developmental stage, LAI and canopy geometry can affect crop $\mathrm{N}$ content (Penuelas et al., 1994). Also, NDVI saturates at values of LAI between 3 and 6, causing low index sensitivity for detection of crop nutritional status (Carlson and Ripley, 1997).

An indirect method to detect canopy $\mathrm{N}$ is by estimating the canopy chlorophyll content (Gitelson et al., 1994), by using the red-edge position of the electromagnetic spectrum, which is the slope of the reflectance located between the red wavelength and the maximum reflectance in the Near-Infrared bands (NIR). It is a very narrow part of the spectrum, but its changes are very sensitive to the chlorophyll content and it can be thought as the boundary between chlorophyll absorption (Red) and leaf scattering (near infrared) (Demetriades-Shah, 1990).

The time of season when those spectral readings are made is an important parameter to consider for both early prediction of nitrogen deficiencies and its subsequent management. For example, on wheat the targeted growth stage might be around DC 31, which corresponds to the first node detectable at stem elongation (Zadoks et al., 1974), when quantify nitrogen stress on crops is useful for the nitrogen fertilisation.

Raun et al. (2001) successfully used remote sensing for developed an algorithm that adjusts top-dress $\mathrm{N}$ application by integrating in-season prediction of wheat yield, PPNT, within season mineralisation rates and predicted crop $\mathrm{N}$ removal.
The potential yield was estimated by two NDVI readings, collected between January and March, which were divided by the cumulative Growing Degree Days between the two dates. The determination of the potential yield in the field is done by using well fertilised reference crop. Sensors mounted directly on applicator machines are used to adjust nitrogen fertilisation in real time; the sensors read canopy colours of the field and apply the proper nitrogen rate based on the canopy colour of the well fertilised reference crop (Blackmer and Schepers, 1995). The use of well fertilised crops as a reference has limited use in rainfed agriculture. The reference crop is supposed to reflect the potential growth of a canopy in that particular environment; provided no stresses are present. Then, when the remote sensing is used elsewhere in the field, the differences in growth rates are quantified and the fertilisation is adjusted with the aim of increase the final yield. However, in rainfed agriculture, where water is the most limiting factor, the reference plot might not reflect the potential growth; water will limit it and an additional fertilisation will not increase the final yield (Loomis and Connor, 1991).

In rainfed environments there are two major problems for the assessment of canopy nitrogen with remotely sensed vegetation indices, namely the effects of soil reflectance and water stress. In addition, in these environments the presence of both water and nitrogen stress can cause confounding effects on the estimation of crop nutrient requirements because water deficiency can mask the crop spectral response for nitrogen stress through changes in reflectance patterns in the Near-Infrared (NIR) and middle infrared reflectance (Rodriguez et al., 2005).

The use of thermal images along with reflectance measurements might help to improve the prediction for an in-season nitrogen application even though they do not completely remove the soil effects (Tilling et al., 2007). Some indices have been developed for this particular purpose, such as the Canopy Chlorophyll Content Index (CCCI; Barnes et al., 2000), which is based on a planar domain approach, where two vegetation indices, the NDVI and the NDRE (Normalised Difference Red Edge; Barnes et al., 2000), were used as a surrogate for canopy cover and leaf N. For instance, the combination of this index and some classical vegetation indices gave useful information regarding the de- 
gree of nitrogen stress (El-Shihka et al., 2007).

Understanding the $\mathrm{N}$ fertilization efficiency might require the availability of long-term studies, because few years of field experiments might not reflect the potential crop response, due to variation in growing season rainfall. Process-oriented crop growth models can be useful to simulate the long-term effects of water and $\mathrm{N}$ stresses and their temporal interactions on daily crop growth and development rates through the growing season (Batchelor et al., 2002; Basso et al., 2007). They have been extensively validated and applied under a wide range of environmental conditions (Singh, 1985; Carberry et al., 1989; Jagtap et al., 1993; Kiniry et al., 1997; Garrison et al., 1999; Miao, et al., 2006; Basso et al., 2007, 2009; Senthilkumar et al., 2009).

Crop simulation models have the potential to integrate the effects of temporal and multiple stresses interaction on crop growth under different environmental and management conditions (Basso et al., 2001). The strength of these models is their ability to account for stress by simulating the temporal interaction of stress on plant growth each day during the season (Batchelor et al., 2002). However, crop simulation models cannot simulate every position in the field because of the costs associated with gathering data and the availability of detailed inputs. As a consequence, delineating zones within the field of similar crop response may provide the right amount of data to execute the model (Basso et al., 2007). Various authors have proposed criteria for the delineation of management zones (Mulla, 1991; Fleming et al., 2001; Ferguson et al., 2004; Schepers et al., 2004; Chang et al., 2004; Inman et al., 2005: Franzen et al., 2002; Basso et al., 2009).

The objective of this paper is to present a procedure that allows for the selection of optimal nitrogen fertilizer rates to be applied spatially on previously identified management zones through crop simulation modelling.

\section{Methodology}

\section{Site Description}

The study was carried out on a 10 ha field with rolling landscape, located in the S. Agata delle Tremiti, Serracapriola (FG) $\left(41^{\circ} 48^{\prime} 46^{\prime \prime} \mathrm{N}, 15^{\circ}\right.$
93’ 99" E; 40 m a.s.l.), Foggia - Italy, during 7 crop seasons of wheat monoculture (from $2001 / 02$ to 2008/09). The field is characterized by 3 different yielding zones (Basso et al., 2009) and soil type (Fig. 1):

1) a high yielding zone (High Yield Zone) with silty loam soil, $1.3 \%$ organic carbon (OC), $150 \mathrm{~mm} \mathrm{~m}^{-1}$ of potential extractable soil water (PESW);

2) a medium yielding zone (Medium Yield Zone) with a sandy loam soil and 1.2\% (OC), $130 \mathrm{~mm} \mathrm{~m}^{-1}$ PESW;

3) a low yielding zone (Low Yield Zone) with coarse and stony soil, $100 \mathrm{~mm} \mathrm{~m}^{-1}$ of PESW, even though this area has a shallow soil $(60 \mathrm{~cm})$ reducing further the PESW to only $60 \mathrm{~mm}$.

The climate of the area was characterized by an average annual rainfall of about $400 \mathrm{~mm}$. The annual average maximum temperature was 18 ${ }^{\circ} \mathrm{C}$, with a minimum of $6{ }^{\circ} \mathrm{C}$.

The sampling scheme was made by adopting a $25 \mathrm{~m} \times 25 \mathrm{~m}$ grid. There were 25 sampling points, which were identified using of a DGPS (Trimble AgGPS 114). The points were located at the nodes of the grid and measurements were taken on the point of sampling at three different distances from the node $(1,3$ and $5 \mathrm{~m})$. A Digital Elevation Model (DEM) was obtained using the DGPS a resolution of $5 \mathrm{~m}^{2}$ and with cm level DGPS accuracy.

\section{Agronomic management}

The crop planted was durum wheat (Triticum Durum, Desf.) cultivar 'Quadrato' for the first 3 crop seasons, then Ciccio and Simeto for the rest of the crop seasons. For all crop seasons the seedbed was prepared in September with a plough at a depth of $30 \mathrm{~cm}$. The sowing was made in December at depth of $5 \mathrm{~cm}$ and $17 \mathrm{~cm}$ distance between the rows. The Nitrogen (N) fertilization consisted in two split-applications, one at sowing with $25 \mathrm{~kg} \mathrm{~N} \mathrm{ha}^{-1}$ as Diammonium Phosphate and another at tillering with 65 $\mathrm{kg} \mathrm{N} \mathrm{ha-1}$ as Urea. Weed control was accomplished using RoundUp (Glifosate) and Topik + Sound (2.4D+ CLODIFOP + Metosulan) for all crop seasons. The crop was harvested always around the first decade of June.

\section{Soil Sampling}

The soil samples were taken in November 2001 prior planting to determine the soil chemical 


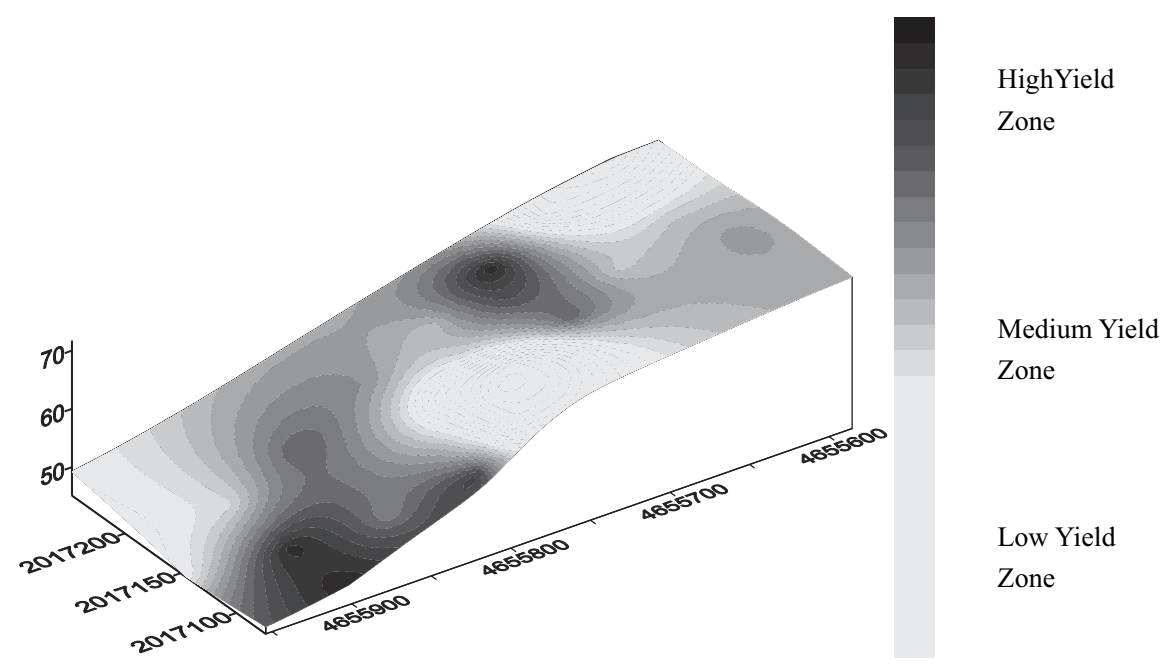

Figure 1. Maps of the three management zones. High Yield Zone; Medium Yield Zone, Low Yield Zone (Basso et al., 2009). properties to use as input in the simulation model. Four depths were sampled with an increment of $15 \mathrm{~cm}$ up to a total depth of $60 \mathrm{~cm}$. Soil texture was determined using the hydrometer method (Klute, 1986), Organic Carbon (C) was measured using the Walkley-Black method (Walkley and Black, 1934), total N was determined using Kjedahl method, $\mathrm{K}$ exchangeable, cation exchange capacity (CEC) and $\mathrm{P}$ exchangeable were determined with the Olsen method. Soil water content was measured using the gravimetric method every three weeks for the sampling points selected every $20 \mathrm{~cm}$ increment to a total depth of $60 \mathrm{~cm}$ (where possible). The sampling points located at the top of the hill side did not allow reaching the depth of $60 \mathrm{~cm}$, therefore the total depth of those sampling points reach a maximum of 40 $\mathrm{cm}$.

\section{Yield monitoring}

Yield data were recorded by using a New Holland TX 64 combine equipped with a yield monitor system (grain mass flow and moisture sensors). Site coordinates for each yield measurement were determined with a differentially-corrected (OMNISTAR signal) Trimble 132 receiver. The SMS software version 3.0 ${ }^{\mathrm{TM}}$ (AgLeader Tecnology, Inc.) was used to read the row yield data (expressed at 14\% dried matter). Yield data semivariograms were created using GS+ software version 5.3 ${ }^{\mathrm{TM}}$ (Gamma Design Software, 1999).

\section{Crop model description}

Simulation runs were performed using the CERES model for wheat (Ritchie and Otter, 1985); the model is part of the DSSAT 4.0.2 (Decision Support Systems for Agrotechnology Transfer) (Hoogenboom et al., 1994). The model is process-oriented model that simulate plant growth and development responses to environmental conditions (soil and weather), genetics and management strategies.

The weather data used by the model included daily values of incoming solar radiation (MJ $\mathrm{m}^{-2}$ day $^{-1}$ ), maximum and minimum temperature $\left({ }^{\circ} \mathrm{C}\right)$ and rainfall $(\mathrm{mm})$. The measured weather was providing by the meteorological station located near the experimental field. Soil input data (sand, silt, and clay content, bulk density, organic carbon and water limits) were determined from soil samples collected at the 25 locations (see paragraph 2.3). Soil water limits were calculated using the procedure suggested by Ritchie et al. (1999). The soil water limit used to execute the model varied spatially using sitespecific input according to the observed data of soil texture, soil depth, coarse fraction and initial soil water content. The model performance was evaluated using the root mean square error (RMSE). The simulated yields were compared with the measured yield for the study site. An additional validation was carried out using the long term yield data collected at variety trails experiment of the CRA Cereal Institute since 1976. 
Procedure for selecting optimal $N$ fertilizer rates We selected 7 nitrogen $(\mathrm{N})$ fertilizer rates $(0,30$, $\left.60,90,120,150,180 \mathrm{~kg} \mathrm{~N} \mathrm{ha}^{-1}\right)$ to simulate the impact of $\mathrm{N}$ fertilizer on yield, leaching, and net economic return for 56 years of available weather record. The model quantifies the effect of climate variability of temporal variation of yield, and environmental impact. We simulated the selected $\mathrm{N}$ rates for the previously identified management zones (Basso et al., 2009). We assessed the spatial and temporal variability of yield, leaching and nitrogen marginal values using the simulated cumulative probability analysis. We simulated the $7 \mathrm{~N}$ fertilizer rates for 56 years of available weather record for the site. We then chose the best $\mathrm{N}$ fertilizer rate for each of the zone based on the yield response to $\mathrm{N}$, marginal value and amount of nitrate leaching.

\section{Results and discussion}

The validation of measured and simulated yield for the 56 years was shown in Figure 2. The RMSE was $320 \mathrm{~kg} \mathrm{ha}^{-1}$ demonstrating the reliability of the model used for this study.

The cumulative probability of the simulated yield clearly shows the different effect of $\mathrm{N}$ on each of the zones (Fig. 3 a-c). The High Yield Zone (HYZ) demonstrated to be more responsive to the $\mathrm{N}$ fertilizer supply with a significant increase in the $90 \mathrm{~kg} \mathrm{~N} / \mathrm{ha}$ compared to greater amount that did not increase yield substantial-

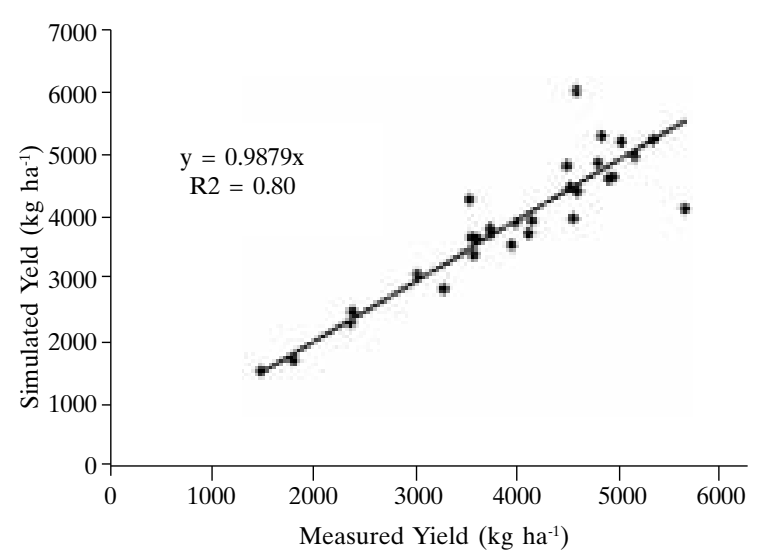

Figure 2. Model validation for the study area (Basso et al., 2007).

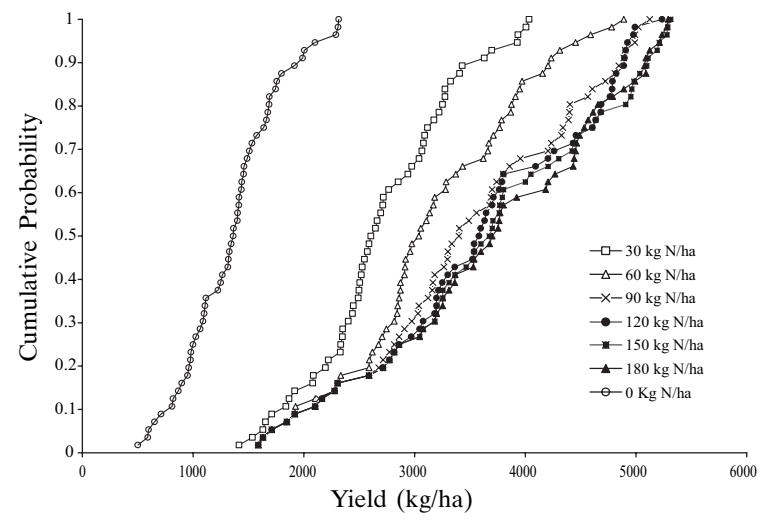

Figure 3a. Cumulative probability function of $\mathrm{N}$ rates and Yield for the HYZ.

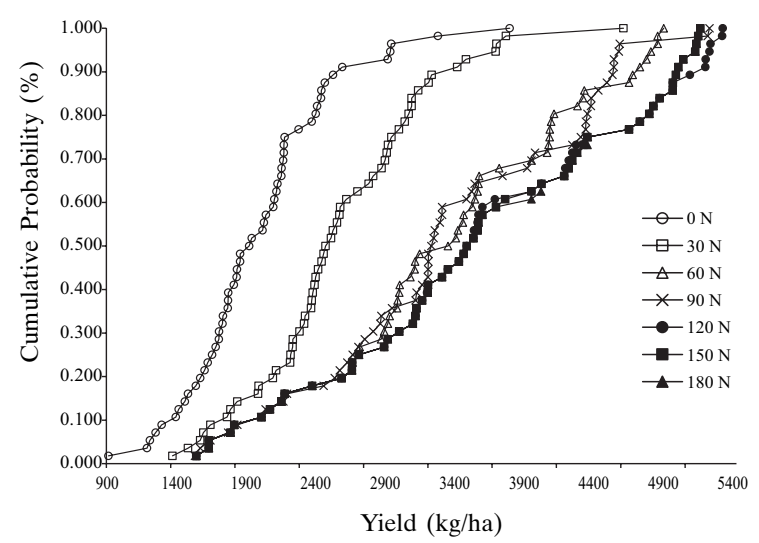

Figure 3b. Cumulative probability function of $\mathrm{N}$ rates and Yield for the MYZ.

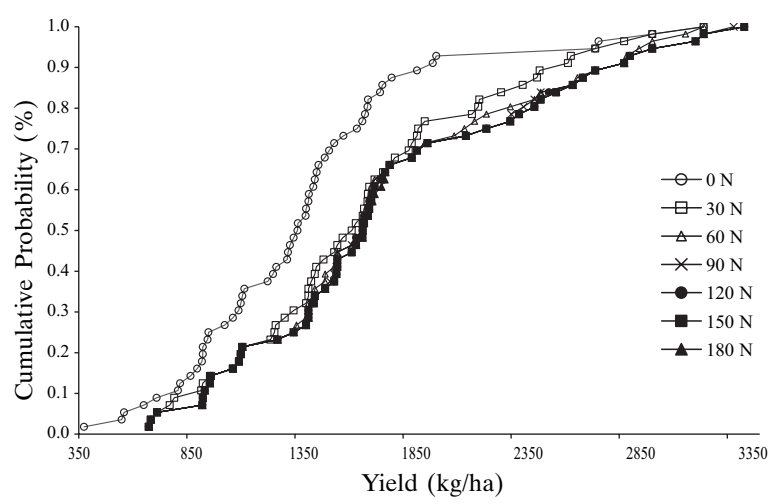

Figure 3c. Cumulative probability function of $\mathrm{N}$ rates and Yield for the LYZ.

ly (Fig. 3a). The Medium Yield Zone (MYZ) showed an increase from 30 to 60 , demonstrating that from 60 onward the $\mathrm{N}$ addition does not guarantee a greater yield (Fig 3b). Low 


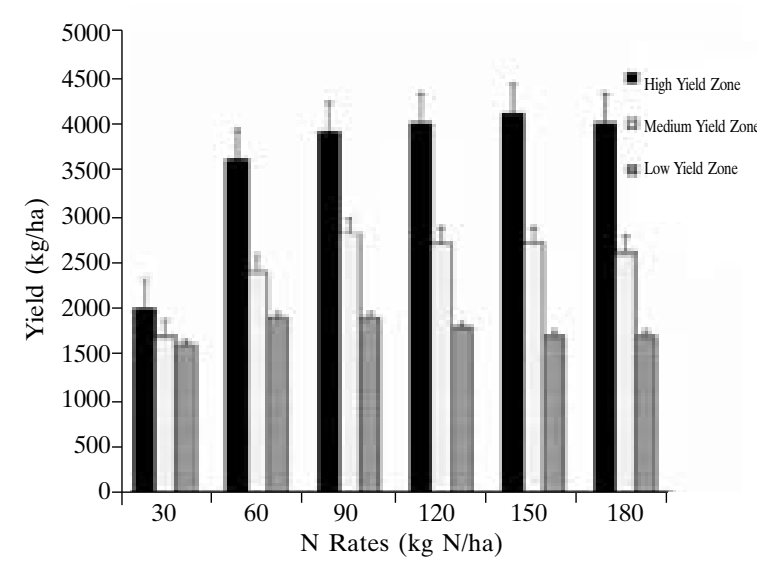

Figure 4. Average yield as function of $\mathrm{N}$ rates for the three management zones.

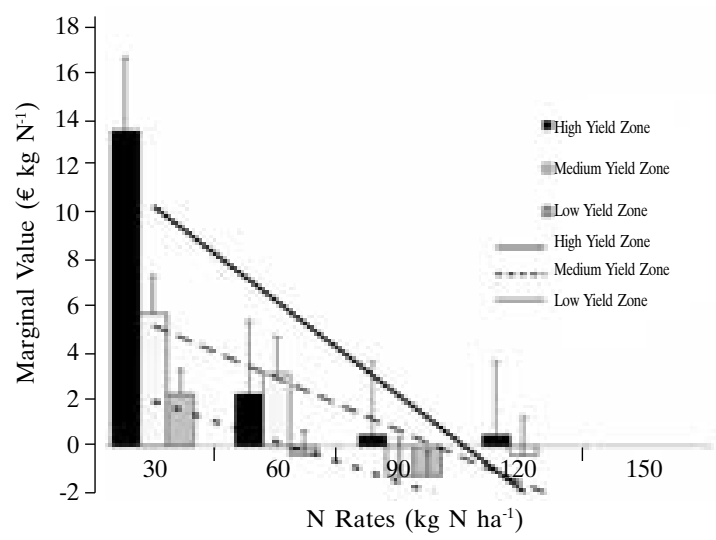

Figure 6. N Marginal value as function of $\mathrm{N}$ rates for the three management zones.

Yield Zone (LYZ) does not show any difference in yield increase after $30 \mathrm{~kg} \mathrm{~N} / \mathrm{ha}$.

Average Grain yield for the three management zones at different $\mathrm{N}$ rates is showed in Figure 4. The High Yield Zone (HYZ) showed the highest yield for all the $\mathrm{N}$ rates; in the HYZ the maximum yield was obtained with $150 \mathrm{~N}$ (4100 kg/ha) even though the difference with from $90 \mathrm{Kg} \mathrm{N} / \mathrm{ha}$ are nearly insignificant. For the Medium Yield Zone (MYZ) the highest yield was obtained with $90 \mathrm{~N}(2800 \mathrm{~kg} / \mathrm{ha})$ while for the Low Yield Zone (LYZ) the same yield of $1900 \mathrm{~kg} / \mathrm{ha}$ was obtained with either 60 or $90 \mathrm{~N}$.

The net revenue calculated as difference between the current grain price and the global costs (operation plus materials), achieved at the different $\mathrm{N}$ rates is showed in Figure 5. For the $\mathrm{HYZ}$ the maximum economical return was

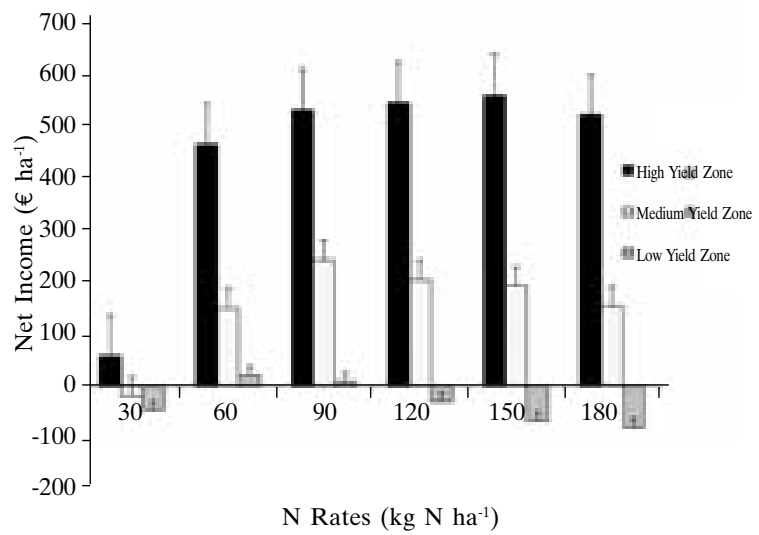

Figure 5. Net income as function of $\mathrm{N}$ rates for the three management zones.

achieved at $150 \mathrm{~N}$, but again the difference with the lower rates are very small, suggesting that the same income can be obtained with lower $\mathrm{N}$ but at the same we save $\mathrm{N}$ fertilizer that is a potential threat to the groundwater through the leaching processes. For the MYZ and LYZ the highest profit was obtained with $90 \mathrm{Kg} \mathrm{N} / \mathrm{ha}$ and $60 \mathrm{Kg} \mathrm{N} / \mathrm{ha}$, respectively.

Figure 6 shows that the marginal return of $\mathrm{N}$ on grain yield decreased as the $\mathrm{N}$ rates increased. The additional $30 \mathrm{~kg} \mathrm{~N} / \mathrm{ha}$ added from the $30 \mathrm{~N}$ showed a diminishing marginal return for all the three zones. The difference in output for the $\mathrm{HYZ}$ was $13.6 € \mathrm{~kg} \mathrm{~N}^{-1}$ for the first $30 \mathrm{~kg} \mathrm{~N} / \mathrm{ha}$, $2.2 € \mathrm{~kg} \mathrm{~N}^{-1}$ for the additional $30 \mathrm{~kg} \mathrm{~N} / \mathrm{ha}$, and $0.46 € \mathrm{~kg} \mathrm{~N}^{-1}$ for the last two $\mathrm{N}$ increases. For the MYZ the marginal return was $5.6 € \mathrm{~kg} \mathrm{~N}^{-1}$ for the first $30 \mathrm{~kg} \mathrm{~N} / \mathrm{ha}, 3.06 € \mathrm{~kg} \mathrm{~N}^{-1}$ for the 60 $\mathrm{N},-1.2$ and $-0.4 € \mathrm{~kg} \mathrm{~N}^{-1}$ for the last two $\mathrm{N}$ increases. For the LYZ the only positive marginal return was for the first $30 \mathrm{~kg} \mathrm{~N} / \mathrm{ha}$ applied $\left(2.2 € \mathrm{~kg} \mathrm{~N}^{-1}\right)$. It dropped to -0.4 and $-1.26 € \mathrm{~kg}$ $\mathrm{N}^{-1}$ for the subsequent $\mathrm{N}$ increases.

The $\mathrm{N}$ leaching for the three zones at different $\mathrm{N}$ rates showed that the leaching increased as the $\mathrm{N}$ rate increased, with the highest values of $\mathrm{N}$ leached obtained for the $180 \mathrm{~N}$ (Fig. 7). However, from the analysis of the 56 years long-term simulations for each area, the cumulative probability function (Fig. 8 a-c) showed that higher $\mathrm{N}$ leaching were obtained for the LYZ and the MYZ, while lower N leaching were observed for the HYZ. This might be due to the best utilization of mineral $\mathrm{N}$ from crop growing in the HYZ respect to the other 


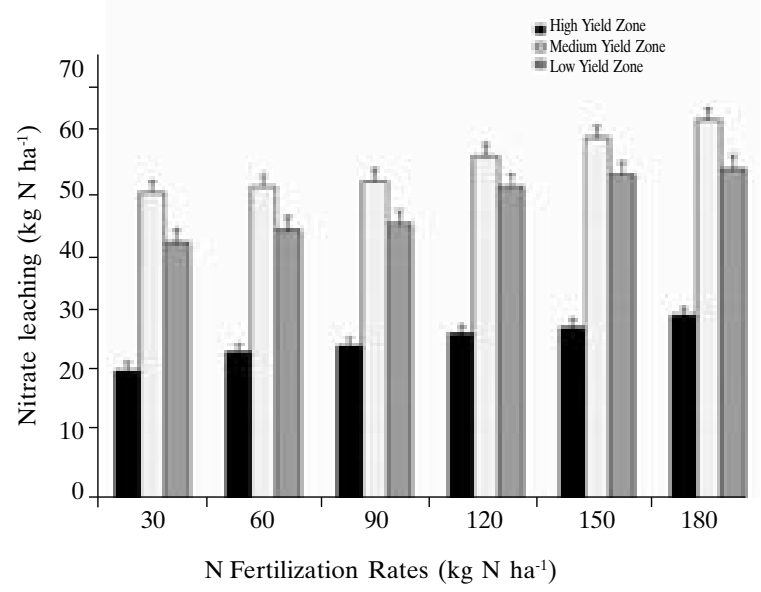

Figure 7. Nitrate leaching as function of $\mathrm{N}$ rates for the three management zones.

two management areas. In the LYZ highest $\mathrm{N}$ value leached was obtained for the 120,150 and $180 \mathrm{~N}$, while for the MYZ the values of $\mathrm{N}$ leached were close for all the $\mathrm{N}$ levels.

The Nitrogen Use Efficiency (NUE) for the different $\mathrm{N}$ treatments and for the three management zones is showed in Figure 9. The HYZ showed higher values of NUE at $30 \mathrm{~N}(53.3 \mathrm{~kg}$ grain $\mathrm{kg} \mathrm{N}^{-1} \mathrm{ha}^{-1}$ ), decreasing to a minimum of -3.3 $\mathrm{kg}$ grain $\mathrm{kg} \mathrm{N}^{-1} \mathrm{ha}^{-1}$ for the $150 \mathrm{~N}$. The MYZ showed a NUE ranging between 23.3 for the 30 $\mathrm{N}$ to $-3.3 \mathrm{~kg}_{\text {grain }} \mathrm{kg} \mathrm{N}^{-1} \mathrm{ha}^{-1}$ for the $150 \mathrm{~N}$; while the LYZ showed values of 10 for the $30 \mathrm{~N}$ to $3.3 \mathrm{~kg} \mathrm{~N}^{-1} \mathrm{ha}^{-1}$ for the $120 \mathrm{~N}$ (Fig. 9).

The increase of grain yield for each unit of $\mathrm{N}$ applied as a function of changes in $\mathrm{N}$ leaching for each unit of $\mathrm{N}$ applied showed that for the $\mathrm{HYZ}$ the $150 \mathrm{~kg} \mathrm{~N} / \mathrm{ha}$ maximized the yield increase as function of $\mathrm{N}$ leached, while for MYZ and LYZ was 90 and 60, respectively (Fig. 10).

When the net revenue is plotted against $\mathrm{N}$ leaching the profitability and the environmental impact of the fertilization management for HYZ respect to MYZ and LYZ is showed (Fig. 11). In fact, as supported by the marginal return, each increase of $30 \mathrm{~N}$ units does not increase significantly the net revenue after 90, 60 and 90 for HYZ, MYZ and LYZ respectively. To note that the LYZ showed a negative value for $30 \mathrm{~kg} \mathrm{~N} / \mathrm{ha}$ because it is necessary to increase the $\mathrm{N}$ supply to have a marginal net return. After $60 \mathrm{~kg} \mathrm{~N} / \mathrm{ha}$, there is a negative impact on the environment with no increase in net marginal return. The MYZ showed a negative

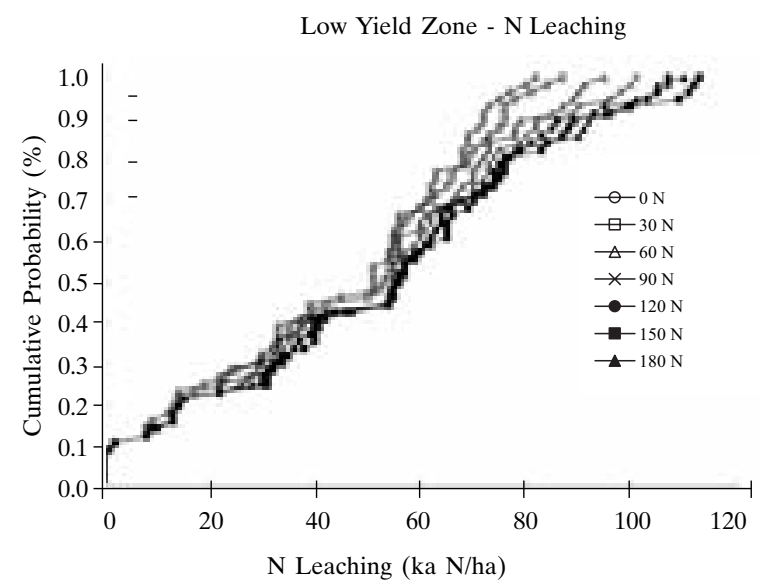

Figure 8a. Cumulative probability function of $\mathrm{N}$ rates and Yield for the LYZ.

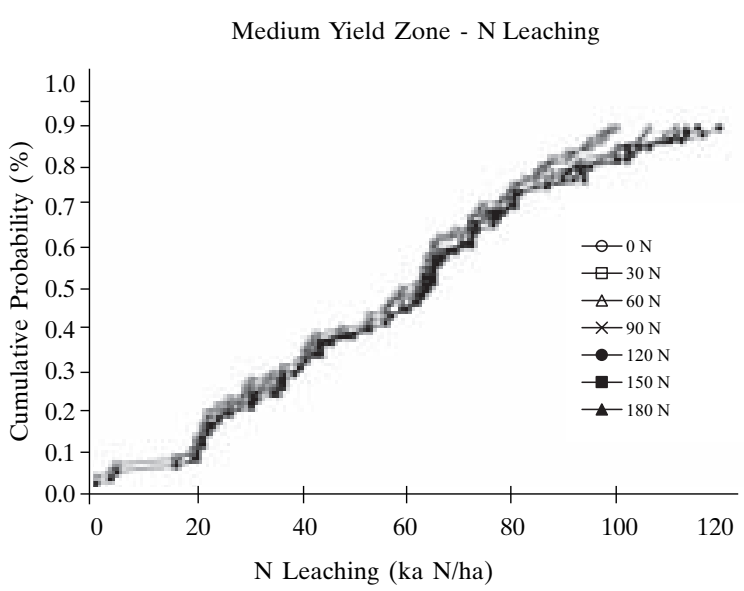

Figure 8 b. Cumulative probability function of $\mathrm{N}$ rates and leaching for the MYZ.

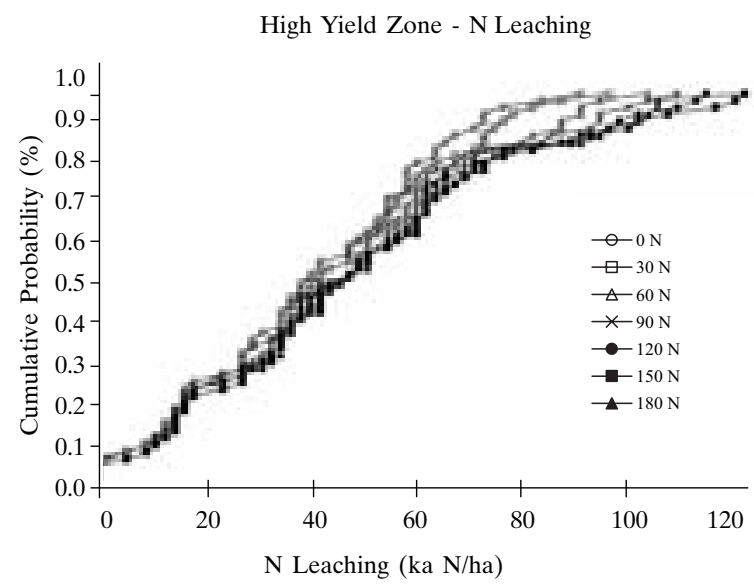

Figure 8c. Cumulative probability function of $\mathrm{N}$ rates and leaching for the HYZ. 


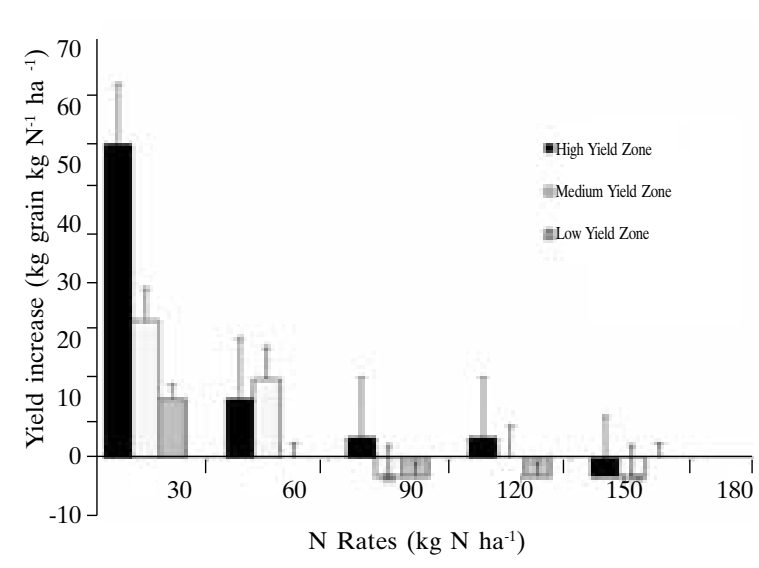

Figure 9. Yield increase as function of $\mathrm{N}$ rates for three management zone

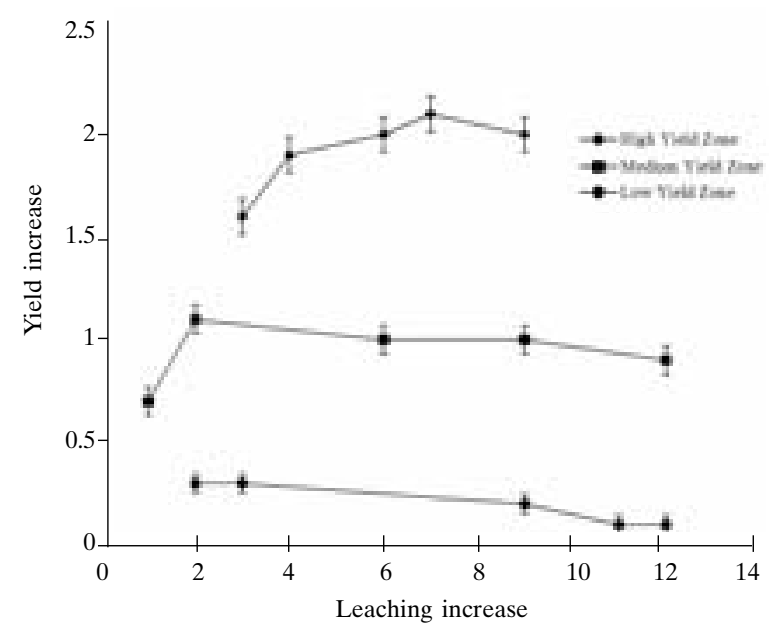

Figure 10. Yield and leaching as function of $\mathrm{N}$ rates for the three management zones.

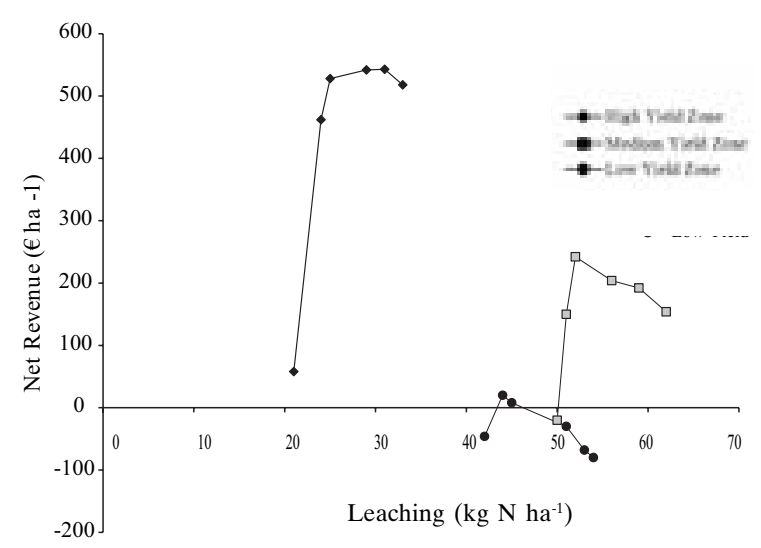

Figure 11. Net revenue and leaching as function of $\mathrm{N}$ rates for the three management zones. Each symbol represent the $\mathrm{N}$ rates starting from $30 \mathrm{Kg} \mathrm{N}^{-1}$ till $180 \mathrm{Kg} \mathrm{N}^{-1}$ with a $30 \mathrm{Kg} \mathrm{N}$ increment. profit at lower $\mathrm{N}$ rates, with increase in revenue at higher $\mathrm{N}$ rates, but at a certain environmental costs, since it shows the highest $\mathrm{N}$ leaching rates. The LYZ is the more sensitive zone for a fertilizer management, because most of the $\mathrm{N}$ rates will not increase the net revenue for that area and only two $\mathrm{N}$ rates showed to be economic viable solution, with $60 \mathrm{~N}$ the optimum rate for such zone.

One of the most important issues arising from the management of $\mathrm{N}$ fertilization for precision agriculture is environmental protection (Pierce and Novak, 1999). The use of crop simulation models, which integrate the effects of complex multiple stresses in a temporal way, allow for a complete understanding of the interaction of the climate and soil effects on crop growth and yield. Sadler et al. (2000) concluded that the application of simulation models to site-specific management is still limited, because models are often not developed or tested for application where there is a certain amount of variability. However, Basso et al. (2007; 2009) showed that crop models were able to simulate yield in a spatial context in a field where a certain degree of variability existed.

\section{Conclusions}

This study has demonstrated that once the management zones have been well defined, crop models can be useful tools in selecting the most sustainable $\mathrm{N}$ management from the agronomic, economic and environmental point of view. Models help finding the best management option regarding the $\mathrm{N}$ rate that will maximize farmer's economical return and reducing the risk of environmental pollution. In fact, the $\mathrm{N}$ rates were different among the zone, with 90$120 \mathrm{~kg} \mathrm{~N} / \mathrm{ha}$ being the best rate for the HYZ, $90 \mathrm{~kg} \mathrm{~N} / \mathrm{ha}$ for the MYZ and $60 \mathrm{~kg} \mathrm{~N} / \mathrm{ha}$ for the LYZ; further increase in $\mathrm{N}$ rates for the MYZ and LYZ would have not cause any yield increase (Fig. 9-11). The best rates for the zones were not identified only by choosing the rate that maximize yield, but the one that will decrease the cost and the environmental impact, and from the analysis of the marginal net return, the net revenue vs. leaching and the NUE. For example for the HYZ results might suggest that $150 \mathrm{~N}$ would have been the optimal rate in 
terms of yield, but the analysis accounting for environmental impact and marginal value of $\mathrm{N}$ suggested that the rate between 90 and $120 \mathrm{~kg} \mathrm{~N} / \mathrm{ha}$ should be the quantity of fertilizer applied to this area, versus 90 and 60 for the MYZ and LYZ.

\section{References}

Angus J.F. 2001. Nitrogen demand by Australian agriculture. Aust. J. Exp. Agric., 4:277-288.

Barnes E.M., Clarke T.R., Richards S.E. 2000. Coincident detection of crop water stress, nitrogen status and canopy density using ground based multispectral data. In: Robert P.C., Rust R.H., Larson W.E. (eds.): Proceedings of the fifth international conference on precision agriculture. Madison, WI, USA: American Society of Agronomy, Unpaginated CD.

Basso B., Ritchie J.T., Pierce F.J., Braga R.P., Jones J.W. 2001. Spatial validation of crop models for precision agriculture. Agric. Syst., 68:97-112.

Basso B., Bertocco M., Sartori L., Martin E.C. 2007a. Analyzing the effects of climate variability on spatial patterns of yield in a maize-wheat-soybean rotation. Europ. J. Agron., 26:82-91.

Basso B., Cafiero G., De Vita P., Castrignanò A. 2007b. Long-term analysis of temporal varibility of durum wheat yield: field study and simulation approach in southern Italy. Proceedings International Conference on Integrated Systems Design. Catania, 11-13 settembre 2007.

Basso B., Cammarano D., Chen D., Cafiero G., Amato M., Bitella G., Rossi R., Basso F. 2009. Landscape position and precipitation effects on spatial variability of wheat yield and grain protein in Southern Italy. J. Agronomy \& Crop Science, 195:301-312.

Batchelor W.D., Basso B., Paz J.O. 2002. Examples of strategies to analyze spatial and temporal yield variability using crop models. Eur. J. Agron., 18:141-158.

Blackmer T.M., Schepers J.S. 1995. Use of a chlorophyll meter to monitor nitrogen status and schedule fertigation for corn. J. Prod. Agric., 8:56-60.

Blankenau K., Olfs H.W., Kuhlmann H. 2000. Effect of microbial nitrogen immobilization during the growth period on the availability of nitrogen fertilizer for winter cereals. Biol. Fert. Soils, 32:157-165.

Bundy L.G., Andraski T.W. 2004. Diagnostic test for sitespecific nitrogen recommendations for winter wheat. Agron. J., 96:608-614.

Carberry P.S., Muchow R.C., McCown R.L. 1989. Testing the CERES-Maize simulation model in a semi-arid tropical environment. Field Crops Res., 20:297-315.

Carlson T.N, Ripley D.A. 1997. On the relation between NDVI, fractional vegetation cover, and leaf area index. Remote Sens. Environ., 62:241-252.

Chang J., Clay D.E., Carlson C.G., Reese C.L., Clay S.A., Ellsbury M.M. 2004. Defining yield goals and man- agement zones to minimize yield and nitrogen and phosphorus fertilizer recommendation errors. Agron. J., 96:825-831.

Connor D.J. 2004. Designing cropping systems for efficient use of limited water in southern Australia. Europ. J. Agron., 21:419-431.

Corbeels M., Hofman G., Van Cleemput O. 1999. Fate of fertiliser $\mathrm{N}$ applied to winter wheat growing on a Vertisol in a Mediterranean environmnent. Nutrient Cycl. Agroecosystems, 53:249-258.

Demetriades-Shah T.H., Steven M.D., Clark J.C. 1990. High resolution derivative spectra in remote sensing. Remote Sens. Environ., 33:55-64.

El-Shikha D.M., Waller P., Hunsaker D., Clarke T., Barnes E. 2007. Ground-based remote sensing for assessing water and nitrogen status of broccoli. Ag. Water Management, 92:183-193.

Everett M.W., Pierce F.J. 1996. Variability of corn yield and soil profile nitrates in relation to site-specific $\mathrm{N}$ management. In: Robert P.C., Rust P.H., Larson W.E. (eds.): Precision Agriculture. Proceedings of the $3^{\text {rd }}$ International Conference, Minneapolis, MN, 43-53.

Ferguson R.B., Lark R.M., Slater G.P. 2004. Approaches to management zone definition for use of nitrification inhibitors. Soil Sci. Soc. Am. J., 67:937-947.

Fleming K.L., Westfall D.G., Wiens D.W., Brodahl M.C. 2001. Evaluating farmer defined management zones for variable rate fertilizer application. Precision Agric., 2:201-215.

Franzen D.W., Hopkins D.H., Sweeney M.D., Ulmer M.K., Halvorson A.D. 2002. Evaluation of soil survey scale for zone development of site specific nitrogen management. Agron. J., 94:381-389.

Gamma Design Software, 1999. GS+: Geostatistics for the environmental sciences, v 3.5. Gamma Design Software, Plainwell, MI, USA.

Garrison M.V., Batchelor W.D., Kanwar R.S., Ritchie J.T. 1999. Validation of the CERES-Maize water and nitrogen balances under tile drained conditions. Agric. Syst., 62, 3:189-200.

Gitelson A.A., Merzlyak M.N. 1994. Quantitative estimation of chlorophyll- $a$ using reflectance spectra: Experiments with autumn chestnut and maple leaves. J. Photochemistry and Photobiology (Biology), 22:247-252.

Glass A.D.M. 2003. N use efficiency of crop plants: physiological contrains upon $\mathrm{N}$ absorption. Critical reviews in plant sciences, 22:453-470.

Grindlay D.J.C. 1997. Towards an explanation of crop nitrogen demand based on the optimization of leaf nitrogen per unit leaf area. J. Agricultural Science, Cambridge, 128:377-396.

Hoogenboom G.J., Jones J.W., Wilkens P.W., Batchelor W.D., Bowen W.T., Huntal L.A., Pickering N., Singh U., Godwin D.C., Baer B., Boote K.J., Ritchie J.T., White J.W. 1994. Crop Models. In: Tsuji G.Y., Uehara G., Balas S. (eds.): DSSAT v. 3, vol. 2-2. University of Hawaii, Honolulu, Hawaii. 
Inman D., Khosla R., Westfall D.G., Reich R. 2005. Nitrogen uptake across site specific management zones in irrigated corn production systems. Agron. J., 97:169-176.

Jackson R.D., Idso S.B., Reginato R.J., Pinter Jr. P.J. 1981. Canopy temperature as a crop water stress indicator. Water Resources Research, 17:1133-1138.

Jagtap S.S., Mornu M., Kang B.T. 1993. Simulation of growth, development and yield of maize in the transition zone of Nigeria. Agric. Syst., 41:215-229.

Kiniry J.R., Williams J.R., Vanderlip R.L., Atwood J.D., Reicosky D.C., Mulliken J., Cox W.J., Mascagni H.J., Hollinger S.E., Wiebold W.J. Evaluation of two maize models for nine U.S. locations. Agron. J., 89:421-426.

Kitchen N.R., Goulding K.W.T. 2001. On-farm technologies and practices to improve nitrogen use efficiency. In: Follet R.F., Hatfield J.L. (eds.): Nitrogen in the environment: Sources, problems and management. Elsevier Science BV, Amsterdam, The Netherlands, 334370.

Klute A., Dirkens C. 1986. Hydraulic conductivity and diffusivity: laboratory methods. In: Klute A. (ed.): Methods of soil analysis: Part 1. Physical and mineralogical methods, $2^{\text {nd }}$ edn. ASA, Madison, WI, 687734.

Kyveryga P.M., Blackmer A.M., Zhang J. 2009. Characterizing and classifying variability in corn yield response to nitrogen fertilization on subfield and field scale. Agron. J., 101:269-277.

LeMaire G., Gastal F. 1997. N uptake and distribution in crop canopies. In: Lemaire G. (ed.): Diagnosis of the Nitrogen status in crops, 3-43. Heidelberg: Springer-Verlag.

Loomis R.S., Connor D.J. 1991. Crop Ecology: Productivity and management in agricultural systems. Cambridge University Press.

Lory J.A., Scharf P.C. 2003. Yield goal versus delta yield for predicting fertilizer nitrogen need in corn. Agron. J., 95:994-999.

Meisinger J.J. 1984. Evaluating crop-available nitrogen in soil-crop systems, 291-416. In: Nitrogen in crop production. ASA, CSSA, and SSSA, Madison, WI.

Miao Y., Mulla D.J., Batchelor W.D., Paz J.O., Robert P.C., Wiebers M. 2006. Evaluating management zone optimal nitrogen rates with a a crop growth model. Agron. J., 98:545-553.

Moran M.S., Clarke T.R., Inoue Y., Vidal A. 1994. Estimating crop water deficit using the relation between surface-air temperature and spectral vegetation index. Rem. Sens. Environ., 49:246-263.

Moran M.S., Pinter P.J. Jr., Clothier B.R., Allen S.G. 1989. Effect of water stress on the canopy architecture and spectral indices of irrigated alfalfa. Remote Sens. Environ., 29:251-261.

Mulla D.J. 1991. Using geostatistics and GIS to manage spatial patterns in soil fertility. In: Kranzler G. (ed.): Proceedings of the Automated Agricultural for the 21st Century. Chicago, IL, 16-17 December 1991. ASAE, St. Joseph, MI.

Mulla D.J., Bhatti A.U., Hammond M.W., Benson J.A. 1992. A comparison of winter wheat yield and quality under uniform versus spatially variable fertilizer management. Agr. Ecos. Environ., 38:301-311.

Penuelas J., Gamon J.A., Fredeen A.L., Merino J., Field C.B. 1994. Reflectance indices associated with physiological changes in nitrogen- and water- limited sunflower leaves. Remote Sens. Environ., 48:135-146.

Phillips S.B., Warren J.G., Keahey D.A., Mullins G.L. 2004. Nitrogen management for white potato production. Crop, soil and environmental sciences publication, Virginia State University.

Pierce F.J., Anderson N.W., Colvin T.S., Schueller J.K., Humberg D.S., Mc.Laughlin N.B. 1997. Yield mapping. In: Pierce F.J., Sadler E.J. (eds.): The state of Site Specific Management for Agriculture. ASA Misc. Publ., ASA, CSSA, and SSSA, Madison, WI, 211-243.

Pierce F.J., Nowak P. 1999. Aspects of precision agriculture. Adv. Agron., 67:1-85.

Raun W.R., Johnson G.V. 1999. Improving Nitrogen use efficiency for cereal production. Agron. J., 91:357-363.

Raun W.R., Soile J.B., Johnson G.V., Stone M.L., Lukina E.V., Thomason W.E., Schepers J.S. 2001. In-season prediction of potential grain yield in winter wheat using canopy reflectance. Agron. J., 93:131-138.

Rice C.W., Havlin J.L., Schepers J.S. 1995. Rational nitrogen fertilization in intensive cropping systems. Fertilizer Res., 42:89-97.

Ritchie J.T., Basso B. 2008. Water use efficiency is not constant when crop water supply is adequate or fixed: the role of agronomic management. Europ. J. Agron., 28:273-281.

Ritchie J.T., Gerakis A., Suleiman A. 1999. Simple model to estimate field-measured soil water limits. Trans. ASAE 42, 1609-1614.

Robert P.C. 1993. Characterisation of soil conditions at the field level for soil specific management. Geoderma, 60:57-92.

Rodriguez D., Sadras V.O., Christensen L.K., Belford R. 2005. Spatial assessment of the physiological status of wheat crops as affected by water and nitrogen supply using infrared thermal imagery. Aust. J. Agric. Res., 56:983-993.

Rouse J.W. Jr., Haas R.H., Schell J.A., Deering D.W. 1973. Monitoring vegetation systems in the Great Plains with ETRS. P. 309-317. Proc. Earth Res. Tech. Satellite-1 Symp., Goddard Space Flight Cent., Washington, DC. 10-14 December 1973.

Sadler E.J., Bauer P.J., Busscher W.J. 2000. Site-specific analysis of a droughted corn crop: I. growth and grain yield. Agron. J., 92:395-402.

Sambroski S.M., Tremblay N., Fallon E. 2009. Strategies to make use of plant sensors-based diagnostic information for Nitrogen recommendations. Agron. J., 101:800-816. 
Scharf P.C., Kitchen N.R., Sudduth K.A., Davis J.G. 2006. Spatially variable corn yield is a weak predictor of optimal nitrogen rate. Soil Sci. Soc. Am. J., 70:2154-2160.

Schepers A.R., Shanahan J.F., Liebig M.A., Schepers J.S., Johnson S.H., Luchiari Jr. A. 2004. Appropriateness of management zones for characterizing spatial variability of soil properties and irrigated corn yields across years. Agron. J., 96:195-203.

Schlemmer M.R., Francis D.D., Shanahan F.F., Schepers J.S. 2005. Remotely measuring chlorophyll content in corn leaves with differing nitrogen levels and relative water content. Agron. J., 97:106-112.

Schmidt J.P., Dellinger A.E., Beegle D.B. 2009. Nitrogen recommendations for corn: an on-the-go sensor compared with current recommendation methods. Agron. J., 101:916-924.

Senthil Kumar P.S., Aruna Geetha S. 2009. A Holistic GIS-based Approach for Thematic Extraction of the Soil Erosion Estimates Using Predictors as a Function of Climate, Land Cover, Relief, Soil and Topography. Asian J. of Water Env. and Pollution, 6:73-78.

Singh U. 1985. A crop growth model for predicting corn
(Zea mays L.) performance in the tropics. Ph.D. Thesis, University of Hawaii, Honolulu, Hawaii, USA.

Tilling A.K., O'Leary G.J., Ferwerda J.C., Jones S.D., Fitzgerald G.J., Rodriguez D., Belford R. 2007. Remote sensing of nitrogen and water stress in wheat. Field Crop Res., 104:77-85.

Verhagen J., Bouma J. 1997. Modelling soil variability. In: Pierce F.J., Sadler E.J. (eds.): The state of Site Specific Management for Agriculture. ASA Misc. Publ., ASA, CSSA, and SSSA, Madison, WI, 55-68.

Vitosh M.L., Silva G.H. 1996. Factors affecting potato petiole sap nitrate test. Soil Sci. Plant Analysis, 27:1137-1152.

Walkley A., Black I.A. 1934. An examination of the Degtjareff method for determining organic carbon in soils: Effect of variations in digestion conditions and of inorganic soil constituents. Soil Sci., 63:251-263.

Zadoks J.C., Chang T.T., Konzak C.F. 1974. A decimal code for the growth stages of cereals. Weed Research, $14: 415-421$.

Zhang H., Smeal D., Arnold R.N., Gregory E.J. 1996. Potato nitrogen management by monitoring petiole nitrate level. J. Plant Nutr., 19:1405-1412. 